\title{
PESQUISA CIENTÍFICA: \\ CONHECIMENTO E PERCEPÇÃO DOS ACADÊMICOS DE ADMINISTRAÇÃO EM CAXIAS DO SUL
}

Sandro Manoel Machado ${ }^{1}$ Andrea Cristina Fermiano Fidelis ${ }^{2}$ Isaias Ricardo Carraro ${ }^{3}$ Pelayo Munhoz Olea ${ }^{4}$

\section{Resumo}

A partir da graduação, a metodologia da pesquisa passa a desempenhar um papel fundamental no desenvolvimento e preparo dos acadêmicos para a elaboração de pesquisas científicas. Tendo por base os critérios e o rigor científico que as pesquisas demandam, este estudo tem por objetivo verificar o nível de conhecimento dos alunos quanto à classificação da pesquisa científica e avaliar como eles percebem seu nível de conhecimento no que tange à classificação da pesquisa científica, quanto a sua natureza, abordagem, objetivos e procedimentos técnicos. $\mathrm{O}$ estudo foi realizado com uma amostra de 239 acadêmicos de Administração de Empresas, em cinco instituições de ensino superior da cidade de Caxias do Sul - RS, utilizando questionários estruturados, de abordagem quantitativa e com finalidade descritiva. Os resultados encontrados apontaram que a maioria dos discentes apresenta desconhecimento ou conhecimento superficial quanto à metodologia da pesquisa científica.
Palavras-chave: pesquisa científica, acadêmicos, administração de empresas, conhecimento.

\section{$* * *$}

1 Mestre, e-mail: sandromanoel@uol. com.br

2 Mestre, e-mail: acris. fidelis@gmail.com

3 Mestre, e-mail: isaias. carraro@gmail.com

4 Doutor, e-mail: pelayo. olea@gmail.com 


\section{INTRODUÇÃO}

No contexto atual, os cursos de graduação no Brasil estão estruturados para solicitar uma pesquisa como Trabalho de Conclusão de Curso (TCC). Para que tenham validade acadêmica, as pesquisas devem atender a critérios e regras preestabelecidos pelas Instituições de Ensino Superior (IES) e pela comunidade científica. Neste sentido, como forma de subsidiar o conhecimento para os acadêmicos sobre metodologia da pesquisa, as IES, via de regra, possuem, suas grades curriculares, disciplinas que contemplam o tema.

Embora seja possívelidentificar a abrangênciae aplicação de disciplinas direcionadas ao estudo dasbasesdametodologiadapesquisa, pouco pode ser evidenciado sobre uma relativa padronização quanto aos conteúdos abordados nestas disciplinas nos cursos de graduação e, menos ainda, sobre a efetividade do aprendizado. Consoante a isto, alguns autores (PRODANOV; FREITAS, 2013; LINHARES, 2014; MESQUITA et al., 2014) indicam que existem etapas importantes a serem delineadas para obter assertividade na elaboração das pesquisas. Caso o processo de planejamento e organização da pesquisa não esteja construído adequadamente, respeitando as etapas metodológicas, a análise e os resultados estarão comprometidos, não permitindo a geração de conhecimento acadêmico.

Cabe ressaltar que, além do caráter científico das pesquisas acadêmicas, especialmente no que se refere aos cursos de administração de empresas,os estudos também compreendem um enfoque em termos práticos que possibilita a sua aplicação e contribuição no meio empresarial, proporcionando uma relação convergente entre a teoria e a prática.
DA MESMA FORMA, AO

PRATICAR E DESENVOLVER

AS FERRAMENTAS DA

METODOLOGIA DA PESQUISA,

OS ALUNOS PASSAM A

CRIAR CONDIÇÕES DE

APRIMORAMENTO PARA

FOMENTAR DE MODO

ESTRUTURADO O UNIVERSO DAS

PESQUISAS CIENTÍfiCAS QUE, AO

MESMO TEMPO, FAVORECEM AS

PERSPECTIVAS PARA RESOLUÇÃO

DE PROBLEMAS E TOMADA

DE DECISÕES POR PARTE DAS

ORGANIZAÇÕES.

Conforme Adams et al. (2014), as pesquisas em administração são conduzidas por inúmeras razões, objetivando atender às demandas específicas de cada estudo proposto e do problema de pesquisa.Portanto, este é o direcionador para conhecer novas descobertas, em que a discussão deve ser uma forma de encontrar, conhecer e entender algo original sobre determinado tema.

Com base nesses apontamentos, o estudo tem por objetivo verificar o conhecimento dos alunos quanto à classificação da pesquisa científica e, em uma segunda etapa, de modo específico, verificar como estes alunos percebem seu nível de conhecimento no que tange à classificação da pesquisa científica.

A pesquisa teve como foco os acadêmicos do curso superior em administração de cinco instituições da cidade de Caxias do Sul-Rio Grande 
do Sul, os quais obrigatoriamente precisavam ter concluído a disciplina referente à metodologia de pesquisa científica.

A cidade de Caixas do Sul, segundo Instituto Brasileiro de Geografia e Estatística - IBGE,é a segunda maior cidade do estado gaúcho, com uma população de 435.564 (quatrocentos e trinta e cinco mil, quinhentos e sessenta e quatro) habitantes. Também, segundo o Ministério da Educação - MEC (2014), é a segunda cidade do estado em número de matriculas no ensino superior, totalizando 42.714 (quarenta e dois mil setecentos e quatorze) alunos no ano de 2013. Ainda no âmbito da educação de nível superior, existem, de acordo com dados do Ministério da Educação, treze (13)IES presenciais em Caxias do Sul, sendo que dez (10) destas ofertam o curso de administração.

O estudo demonstra a sua importância ao abordar e avaliar o nível de conhecimento das bases da pesquisa científica por parte dos alunos, podendo propiciar não só aos próprios discentes, mas à comunidade científica como um todo, maior entendimento sobre a relevância do tema, dado o rigor científico que os trabalhos e publicações acadêmicas demandam, seguidas das oportunidades de aprimoramento evidenciadas na pesquisa. Para tanto, o estudo foi realizado com a utilização de questionário estruturado, de abordagem quantitativa, com finalidade descritiva.

\section{REFERENCIAL TEÓRICO}

O referencial teórico foi estruturado e dividido em três etapas: Pesquisas Científicas, Classificações das Pesquisas e Pesquisas no âmbito da Graduação.

\subsection{PESQUISA CIENTÍFICA}

Para Demo (2000), a pesquisa científica é entendida como procedimento de fabricação do conhecimento e de aprendizagem (princípio científico e educativo), sendo parte integrante de todo processo reconstrutivo do conhecimento. As pesquisas devem contribuir para o aluno, na construção do seu saber e para o meio acadêmico, porque a finalidade de pesquisa é “[...] resolver problemas e solucionar dúvidas, mediante a utilização de procedimentos científicos."(BARROS; LEHFELD, 2000, p. 14).
Segundo Barros E

LEHFELD (2007), A PESQUISA

CIENTÍfICA É UMA FORMA

ORDENADA DE PROCESSOS E

TÉCNICAS EMPREGADAS NA

INVESTIGAÇÃO E NA BUSCA

DO CONHECIMENTO. TODA A

PESQUISA CIENTÍfICA NECESSITA

DE UM MÉTODO APROPRIADO

PARA SUA INVESTIGAÇÃO,

PORQUE TODA A INVESTIGAÇÃO

CIENTIfICA SEGUE PASSOS

RIGOROSOS DENTRO DE SUA

METODOLOGIA PARA PLANEJAR,

EXECUTAR E AFERIR SEUS

DADOS, COM CONCLUSÕES

LÓGICAS DE CARÁTER

ACADÊMICO CIENTÍfiCO. 
Conforme Prestes, Andreola e Olea (2011), a disciplina de metodologia da pesquisa possui relevância que excede o seu conteúdo em si, uma vez que se mostra fundamental na preparação dos discentes também como futuros pesquisadores, propiciando a observação da realidade à luz da teoria. Para uma pesquisa ser confiável, ela deve seguir padrões do método científico, pois seu conceito está associado à ideia de direção, caminho com rigor científico, através de normas e regras preestabelecidas.

Os métodos científicos de pesquisa são entendidos como um conjunto de normas disponíveis que conduzem à captação e ao processamento de informações na investigação de hipóteses científicas (BARROS; LEHFELD,2007). Cooper e Schindler (2003, p. 33) definem as pesquisas científicas em Administração como “[...] uma investigação sistemática que fornece informações para orientar decisões empresariais". Com objetivos de produzir conhecimento para uma ação e tomada de decisão no meio empresarial, os autores salientam que as pesquisas, para serem consideradas respeitáveis, devem seguir o método científico, sendo planejadas e conduzidas com rigor para gerar resultados confiáveis.

Os autores listam nove (09) ações que garantem uma pesquisa de qualidade: (i) Propósito claramente definido; (ii) processo de pesquisa detalhado; (iii) projeto de pesquisa totalmente planejado; (iv) limitações reveladas francamente; (v) altos padrões éticos aplicados; (vi) análise adequada às necessidades do tomador de decisão; (vii) resultados apresentados de forma clara; (viii) conclusões justificadas e (ix) experiência refletida do pesquisador.

Nesse sentido, é relevante ter clareza sobre o que é o conhecimento científico, caracterizado por Lakatos e Marconi (1991) como: real (se dá com base em fatos); contingente (suas hipóteses são testadas por experimentação); sistemático (segue uma ordem lógica que se fundamenta em uma teoria); verificável (suas hipóteses passam pelo processo de verificabilidade); falível (não é conhecimento que se pretenda correto eternamente); aproximadamente exato (um novo arcabouço de proposições e técnicas pode mudar o que entendemos como correto ou verdadeiro). Essas características trazem consigo a importância da formação metodológica para qualquer cientista.

\subsection{CLASSIFICAÇÕES DAS PESQUISAS}

Há diferentes tipos de pesquisas, contudo todas elas buscam estudar através de metodologia científica uma situação problema. As pesquisas científicas são classificadas quanto à natureza, objetivos, procedimentos técnicos e forma de abordagem.

A PESQUisa BÁsica É AQUELA

SEM OBJETIVO DE AÇÃO

PRÁTICA. SUA finALIDADE É

GERAR NOVOS CONHECIMENTOS

PARA O AVANÇO DA CIÊNCIA

ENVOLVENDO VERDADES

UNIVERSAIS.

\subsubsection{Quanto a Natureza}

Pode ser Básica (pura) ou Aplicada. 
A pesquisa Aplicada, diferentemente da Básica, propõe estudar uma questão local com implicações práticas e soluções de problemas. Também objetiva gerar conhecimento, mas com a finalidade de sua aplicação (PRODANOV; FREITAS, 2013).

Cooper e Schindler (2003) observam que a pesquisa Pura (ou básica) e a Aplicada têm ênfase na solução de problemas. A pesquisa Básica resolve problemas de natureza teórica com pouco impacto direto, e a Aplicada influencia a tomada de decisão, a ação e o desempenho de situações concretas. Segundo Sampieri, Collado e Lucio (2013), a pesquisa científica é entendida como um conjunto de processos sistemáticos e empíricos utilizados para entender um determinado fenômeno, sendo seu caráter universal e tendo como finalidades essenciais a produção de conhecimento e a resolução de problemas.

\subsubsection{Abordagem do problema de pesquisa}

A abordagem do problema de pesquisa pode ser quantitativa ou qualitativa. Contudo, as pesquisas podem ter abordagens associadas entre os dois métodos. O que determinará a escolha da abordagem é o enfoque do pesquisador de como quer analisar o fenômeno ou o problema de pesquisa.

\subsubsection{Abordagem quantitativa}

É a forma de abordagem estatística, que busca coletar, analisar e classificar os dados através de números, fórmulas e tabelas. Trabalha geralmente com grandes amostras, através de percentagem, média, moda, mediana, desviopadrão, coeficiente de correlação, análise de regressão e outros conceitos da matemática estatística. Existem softwares desenvolvidos para realizar análises de pesquisas quantitativas. $\mathrm{O}$ pesquisador deve buscar entre opções de análise quantitativa a que mais se adequa às necessidades de pesquisa de seu objeto, considerando as regras e fórmulas pertinentes do instrumento escolhido. Esta abordagem propicia classificar e comparar dados principalmente em trabalhos que buscam a relação de causa e efeito entre os fenômenos estudados (HAIR, 2005; LINHARES; MESQUITA et al., 2014).

\subsubsection{Abordagem Qualitativa}

É a forma de abordagem em que predomina a interpretação dos fenômenos por meio de observação dos sujeitos que estão interferindo na realidade. São dados que não podem ser considerados apenas pela lógica estatística. Necessitam da participação dinâmica do pesquisador em que este se coloca em campo através de entrevistas, observação direta para coleta e análise dos dados. Não há a necessidade de comprovar ou negar as hipóteses levantadas na pesquisa, o que não elimina a necessidade de escolha de instrumento com validade científica acadêmica, podendo invalidar o processo se não estiver de acordo com os padrões dos métodos de pesquisa (HAIR, 2005; PRODANOV; FREITAS, 2013).

Nos métodos qualitativos, é permitido um detalhamento de dados, além da exploração de contradições e paradoxos.

Essa compreensão vai para além da regularidade e tem por definição os tipos de trabalho de natureza de pesquisa cujos resultados não são alcançados através de procedimentos estatísticos (STRAUSS; CORBIN, 2008). 


\subsubsection{Quanto aos objetivos}

Quanto aos objetivos, a pesquisa pode ser Exploratória, Explicativa e Descritiva.

\subsubsection{Pesquisa Exploratória}

Como o próprio nome já indica, a pesquisa exploratória propicia explorar um tema que está sendo investigado sobre vários pontos de vista, buscando uma delimitação, enfoque ou formulação de hipóteses. Caracteriza-se por ser mais flexível, envolvendo geralmente estudos bibliográficos, entrevistas com envolvidos na situação problema ou exemplos de situações similares (HAIR, 2005; PRODANOV; FREITAS, 2013).

\subsubsection{Pesquisa Explicativa}

É o estudo de um fenômeno em profundidade com controle e manipulação das variáveis. Tem como objetivo explicar o porquê das coisas e suas causas. Para as ciências sociais, torna-se difícil fazer pesquisas explicativas, pela inexistência de controles precisos e manipulação da realidade que este tipo de estudo exige. Geralmente é feita através de observações e busca registrar, classificar, analisar e interpretar os dados (COOPER; SCHINDLER, 2003).

\subsubsection{Pesquisa Descritiva}

Para Köche (2012), Prodanov e Freitas (2013), a pesquisa descritiva visa descrever os fatos observados, os fenômenos e a relação entre variáveis através da análise e interpretação de dados, sem interferência do pesquisador.
As pesquisas na área social, de mercado e psicossociais, como pesquisa de opinião, pesquisa de mercado, geralmente são descritivas.

A diferença entre a pesquisa experimental e pesquisa descritiva está no fato de que a descritiva procura classificar, explicar e interpretar fatos que ocorrem, enquanto a pesquisa experimental pretende demonstrar o modo ou as causas pelas quais um fato é produzido.

\subsubsection{Quanto aos Procedimentos Técnicos}

Quanto aos procedimentos técnicos, as pesquisas podem ser classificadas como: pesquisa documental, pesquisa bibliográfica, pesquisa operacional, pesquisa participante, pesquisa-ação, estudo de caso e pesquisa $e x-$ post-facto (PRODANOV; FREITAS, 2013). Os procedimentos técnicos são a forma como serão organizadas e planejadas a coleta e a análise dos dados, e estão alinhados aos objetivos e propósitos da pesquisa. Cada pesquisa deve ter um procedimento adequado na captação dos dados, correndo o risco do trabalho não ter sucesso,se não for bem escolhido (LINHARES, 2014; MESQUITA et al., 2014).

Para Prodanov e Freitas (2013), uma decisão metodológica insensata e/ou incorreta, seja no planejamento da pesquisa, na sua aplicação ou na seleção dos dados, pode colocar a credibilidade em risco, reforçando a importância de pensar em todas as etapas da pesquisa de forma integrada e planejada. Para completar as subseções apresentadas anteriormente, o quadro formulado por Prodanov e Freitas (2013) resume as questões apresentadas. 
Quadro 1: Tipos de pesquisa e suas características

\begin{tabular}{|c|c|c|c|c|c|}
\hline \multicolumn{3}{|c|}{ tipos de pesquisa } & \multicolumn{3}{|c|}{ características } \\
\hline Natureza & $\begin{array}{c}\text { abordagem } \\
\text { do problema }\end{array}$ & $\begin{array}{c}\text { fins da } \\
\text { pesquisa }\end{array}$ & procedimentos & gerais & $\begin{array}{c}\text { tipos de } \\
\text { instrumento }\end{array}$ \\
\hline \multirow[b]{2}{*}{ Básica } & \multirow[b]{2}{*}{ Quantitativa } & \multirow[b]{2}{*}{ Exploratória } & Bibliográfica & $\begin{array}{l}\text { - Base e m } \\
\text { material já } \\
\text { elaborado. }\end{array}$ & $\begin{array}{c}\text { Fontes } \\
\text { bibliográficas }\end{array}$ \\
\hline & & & Documental & $\begin{array}{l}\text { - Material sem } \\
\text { tratamento } \\
\text { analítico ou } \\
\text { que pode ser } \\
\text { reelaborado; } \\
\text { - Efeitos de } \\
\text { variável - } \\
\text { formas de } \\
\text { controle. }\end{array}$ & $\begin{array}{c}\text { Fontes } \\
\text { secundárias }\end{array}$ \\
\hline \multirow{6}{*}{ Aplicada } & \multirow{6}{*}{ Qualitativa } & \multirow{4}{*}{ Descritiva } & & \multirow[b]{2}{*}{$\begin{array}{l}\text { - Verificar a } \\
\text { relação entre } \\
\text { variáveis. }\end{array}$} & $\begin{array}{l}\text { Plano de } \\
\text { pesquisas }\end{array}$ \\
\hline & & & Experimental & & $\begin{array}{c}\text { Manipulação } \\
\text { de condições } \\
\text { e observação } \\
\text { dos efeitos } \\
\text { produzidos }\end{array}$ \\
\hline & & & Ex-Post-Facto & $\begin{array}{l}\text { - Conhecer o } \\
\text { comportamen- } \\
\text { to; } \\
\text { - Interrogação } \\
\text { direta. }\end{array}$ & $\begin{array}{l}\text { Observação, } \\
\text { questionário } \\
\text { e entrevistas }\end{array}$ \\
\hline & & & Levantamento & $\begin{array}{l}\text { - Levantamento } \\
\text { - um gru- } \\
\text { po ou uma } \\
\text { comunidade; } \\
\text { - Estudo apro- } \\
\text { fundado de } \\
\text { um ou poucos } \\
\text { objetos. }\end{array}$ & $\begin{array}{c}\text { Questionário, } \\
\text { entrevista e } \\
\text { formulário }\end{array}$ \\
\hline & & \multirow[t]{2}{*}{ Explicativa } & $\begin{array}{l}\text { Estudo de } \\
\text { campo }\end{array}$ & & $\begin{array}{c}\text { Variados - } \\
\text { Questionários, } \\
\text { entrevistas, } \\
\text { formulários e } \\
\text { observação }\end{array}$ \\
\hline & & & $\begin{array}{l}\text { Estudo de } \\
\text { caso }\end{array}$ & & $\begin{array}{l}\text { Várias } \\
\text { técnicas }\end{array}$ \\
\hline
\end{tabular}

Fonte: Prodanov e Freitas (2013) 


\subsection{PESQUISAS NO ÂMBITO DA GRADUAÇÃO}

As pesquisas precisam resistir à tentação da busca cada vez mais intensa pelo preciso conhecimento do futuro e, ao contrário disto, desenvolver mecanismos de mobilização do presente como um recurso poderoso que ofereça alternativas e perspectivas para a construção de um futuro melhor (FACER,2013). A pesquisa acadêmica deve ser uma atividade proposta pelos professores e orientadores que despertará o espírito investigativo e o avanço do conhecimento (PRODONAV; FREITAS, 2013).

\section{PARA Linhares (2014),}

CONSTATA-SE QUE A FORMAÇÃO

DOS ACADÊMICOS APRESENTA

CARÊNCIAS NO QUE SE REFERE

À METODOLOGIA E A TÉCNICAS

DE PESQUISA, MESMO ENTRE

OS QUE POSSUEM GRADUAÇÃO

EM CiênCIAS Sociais. EM

OUTROS NÍVEIS ACADÊMICOS,

AS MESMAS DIfICULDADES SÃO

EVIDENCIADAS.

É importante salientar que o pesquisador precisa preocupar-se na organização e no planejamento de sua pesquisa através da escolha dos métodos de pesquisa científica adequada aos seus objetivos. Para Collis e Hussey (2005), a escolha do objetivo de pesquisa varia de acordo com o paradigma adotado (positivista ou fenomenológico), que incidirá sobre a escolha da unidade de análise.Parte-se, então, para o desenvolvimento de uma estrutura teórica, delimitada como um grupo de teorias e modelos da literatura que sustentam um estudo e explicam as questões ou hipóteses de pesquisa.

Collis e Hussey (2005) sustentam, inclusive, que limitações de pesquisa, isto é, seus potenciais pontos fracos, devem ser expostos na seção metodológica do projeto. Por último, recomendam a explanação dos resultados esperados, ainda que o pesquisador não saiba onde chegará com sua investigação.A clareza dessa diferenciação para o pesquisador é de grande importância, pois o método de estudo será escolhido de acordo com a pergunta de pesquisa que se deseja responder.

Conforme Bertero, Caldas e Wood (1999), os profissionais da área de administração constantemente são confrontados com problemas organizacionais, sendo pressionados para a busca de soluções, porém sem o devido tempo para o aprofundamento nos estudos teóricos e reflexões que os direcionem para a tomada de decisão e entendimento do contexto em que estão inseridos.

\section{MÉTODO DE PESQUISA}

Para Hartley (1994), um método por si só não é bom ou ruim, pois o mesmo depende de dois fatores nas pesquisas: o relacionamento entre a teoria e o método e como o pesquisador lida com as potenciais deficiências deste método.
Esta pesquisa, de natureza aplicada, utilizou questionário estruturado, de abordagem quantitativa, com finalidade descritiva, entendendo que estes delineamentos melhor atendiam aos propósitos do estudo. 
Para o desenvolvimento do estudo, foram pesquisados, por amostragem, os acadêmicos do curso de Administração em cinco Instituições de Ensino Superior. devidamente registradas junto ao Ministério da Educação - MEC, representando 77,98\% do total de vagas autorizadas. Os dados detalhados são apresentados na Tabela 01:

As IES foram selecionadas de um universo de 10 instituições da cidade de Caxias do Sul,

Tabela 1: Número de vagas por IES em Caxias do Sul

\begin{tabular}{cccc} 
IES & VAGAS & \% DE VAGAS & SELECIONADAS \\
\hline A & 600 & $26,43 \%$ & $26,43 \%$ \\
\hline B & 600 & $26,43 \%$ & $26,43 \%$ \\
\hline C & 300 & $13,22 \%$ & $13,22 \%$ \\
\hline D & 150 & $6,61 \%$ & $6,61 \%$ \\
\hline E & 120 & $5,29 \%$ & - \\
\hline F & 100 & $4,41 \%$ & - \\
\hline G & 100 & $4,41 \%$ & - \\
\hline H & 100 & $4,41 \%$ & - \\
\hline I & 100 & $4,41 \%$ & -
\end{tabular}

Fonte: Adaptada de Brasil (2014)

Das IES selecionadas (A, B, C, D e E) para a aplicação do questionário de pesquisa, foram desqualificadas as instituições $\mathrm{D}$ e E, em virtude dos discentes do curso de Administração destas instituições não terem cursado a disciplina que aborda os assuntos referentes à metodologia $\mathrm{da}$ pesquisa.Portanto, a análise dos dados colhidos compreendeu as IES denominadas A, B e C, cujo total da amostra foi de 239 acadêmicos pesquisados.
A primeira etapa do questionário aplicado teve por objetivo verificar o nível de conhecimento dos acadêmicos quanto à classificação da pesquisa científica. A segunda etapa do questionário objetivou verificar como os alunos percebem e avaliam o nível de conhecimento quanto à classificação da pesquisa científica. 


\section{AS INSTITUIÇÕES DE ENSINO SUPERIOR}

No Brasil, de acordo com o censo realizado pelo Instituto Nacional de Estudos e Pesquisas Educacionais Anísio Teixeira - INEP, com dados apresentados em 2013, referentes ao censo do ano de 2012, o estado do Rio Grande do Sul possui $16,93 \%$ das Instituições de ensino superior do Brasil. Considerando a Região Sul do país, compreendida pelos estados do Paraná, Santa Catarina e Rio Grande do Sul, a quantidade de IES representa 28,12\%, conforme expresso na Tabela 02:

Tabela 2: Número de IES por Categoria Administrativa

\begin{tabular}{cccccc} 
& \multicolumn{2}{c}{2012} & & & \\
Região & Total & Federal & Estadual & Municipal & Privada \\
\hline Brasil & 2.416 & 103 & 116 & 85 & 2.112 \\
\hline $\begin{array}{c}\text { Regiáo Sul (PR, } \\
\text { SC e RS) }\end{array}$ & 409 & 17 & 15 & 17 & 360 \\
\hline RS & 115 & 9 & 1 & - & 105 \\
\hline
\end{tabular}

Fonte: Adaptada de Brasil (2012)

A cidade de Caxias do Sul tem a segunda maior população do estado do Rio Grande do Sul, com aproximadamente 440.000 habitantes. Também é caracterizada como um polo de desenvolvimento industrial, com reconhecimento nacional. Noâmbito da educação de nível superior, existem 10 instituições na cidade, das quais cinco oferecem o curso de graduação em administração e a partir das quais foi composto o objeto de pesquisa do estudo.

Os questionários foram aplicados aos discentes de três destas IES denominadas como: (i) IES A; (ii) IES B; e (iii) IES C. A instituição A é uma IES com atuação direta na região nordeste do estado do Rio Grande do Sul. Disponibiliza para a comunidade acadêmica oitenta e cinco cursos de graduação. Como instituição, alega estar em permanente diálogo com a sociedade e seus interesses são os da coletividade e o resultado de suas ações é totalmente reinvestido na qualificação institucional. No curso de Administração da IES A, constavam 2.853 (dois mil quinhentos e cinquenta e três) alunos matriculados no primeiro semestre do ano de 2014.

A instituição $B$ oferece atualmente vinte e dois cursos de Graduação. A IES B declara que a pesquisa científica faz parte da rotina do aluno desde o início do curso, concretizando-se em Atividades Práticas Supervisionadas que aproximam o acadêmico do cotidiano que irá encontrar em sua vida profissional. 
Atenta às necessidades educacionais de nível superior, ao traçar as políticas e diretrizes de ensino, pesquisa e extensão, explicita a sua compreensão quanto a uma concepção integrativa de ensino na Educação Superior, enfocando em suas ofertas a convergência entre as necessidades do mercado e as possibilidades de empreendimento. No curso de Administração da IES B, constavam 1.502 (mil quinhentos e dois) alunos matriculados no primeiro semestre do ano de 2014.
A instituição $\mathrm{C}$ oferece atualmente oito cursos de Graduação, que visam desenvolver as habilidades técnicas e de formação geral. Prioriza a oferta de cursos no turno da noite, para que o aluno possa conciliar o trabalhar com os estudos. Considerando-se como Instituição de Ensino Superior de referência, seus cursos atendem às necessidades de uma demanda que busca o aprimoramento profissional para o mercado. No curso de Administração da IES $\mathrm{C}$, constavam 453 (quatrocentos e cinquenta e três) alunos matriculados no primeiro semestre do ano de 2014.

\section{ANÁLISE DE DADOS E DISCUSSÃO DOS RESULTADOS}

A premissa para os respondentes foi de que os graduandos tenham cursado a disciplina que aborda os temas do objeto de pesquisa, durante o semestre em andamento ou em ocasião anterior. Os dados expressos são resultantes das pesquisas aplicadas nas IES: i) A; ii) B; e iii) C.

As duas IES não classificadas ainda não tinham alunos matriculados em disciplinas que abordassem o tema de metodologia da pesquisa, porque estavam nos semestres iniciais do curso de Administração.
Nas IES pesquisadas, 239 (duzentas e trinta e nove) alunos responderam o questionário. Destes, 57,74\% haviam cursado a disciplina nos últimos 03 semestres, tendo em vista que ela é oferecida no final do curso. O período quando foi cursada a disciplina que aborda os temas do objeto de pesquisa com o número de respondentes é detalhado na Tabela 03.

Tabela 3: Quantidade de alunos e o ano em que foi cursada a disciplina

\begin{tabular}{ccc} 
Ano & Respondentes & Percentual \\
\hline 2014 & 66 & $27,62 \%$ \\
\hline 2013 & 72 & $30,12 \%$ \\
\hline Anterior a 2013 & 101 & $42,26 \%$ \\
\hline
\end{tabular}

Fonte: Dos autores (2015) 


\subsection{PRIMEIRA ETAPA DA PESQUISA}

A primeira etapa do questionário, cujo objetivo era verificar o conhecimento quanto à classificação da pesquisa científica, é apresentado na Tabela 04.

Tabela 4: Etapa 01 - Verificação do conhecimento dos alunos nas IES

\begin{tabular}{cccc} 
Classificação da pesquisa científica & Desconhece & Correta & Errada \\
\hline Quanto a sua natureza & 34 & 86 & 119 \\
\hline Quanto à abordagem & 17 & 150 & 72 \\
\hline Quanto aos seus objetivos & 23 & 91 & 125 \\
\hline Quanto aos seus procedimentos técnicos & 41 & 114 & 84 \\
\hline
\end{tabular}

Fonte: Dos autores (2015)

O resumo estatístico sobre a metodologia da pesquisa científica identificada nas IES é apresentado na Tabela 05 .

Tabela 5: Resumo Estatístico - verificação do conhecimento dos alunos

\begin{tabular}{cccc} 
Metodologia da pesquisa científica & Desconhece & Correta & Errada \\
Quanto a sua natureza & $14,2 \%$ & $36,0 \%$ & $49,8 \%$ \\
\hline Quanto à abordagem & $7,1 \%$ & $62,8 \%$ & $30,1 \%$ \\
\hline Quanto aos seus objetivos & $9,6 \%$ & $38,1 \%$ & $52,3 \%$ \\
\hline Quanto aos seus procedimentos técnicos & $17,2 \%$ & $47,7 \%$ & $35,1 \%$ \\
\hline
\end{tabular}

Fonte: Dos autores (2015)

Através da análise dos dados constantes nas quatro perguntas realizadas na primeira etapa da pesquisa, que tange à natureza, à abordagem, aos objetivos e aos procedimentos técnicos, $46,1 \%$ dos alunos pesquisados demonstraram conhecimento quanto à classificação da pesquisa. Considerando que todos os respondentes cursaram a disciplina que aborda os assuntos da pesquisa, o somatório dos itens desconhecimento e respostas erradas com os resultados de $12,06 \%$ e $41,8 \%$, respectivamente, evidencia um baixo grau de conhecimento sobre o tema. Em contrapartida e de modo individual, pode-se destacar positivamente o índice de $62,8 \%$ de respostas corretas referentes ao item abordagem da pesquisa científica, considerando também que os tópicos referentes a objetivos e procedimentos técnicos ficaram abaixo de 50\%.

Os discentes que estavam cursando a disciplina no momento da pesquisa obtiveram um índice de assertividade maior do que os outros que a cursaram em semestres anteriores. Foi evidenciada também, a diferença de resultados entre 
as IES, sendo que a IES A apresentou, dentre as demais, o menor índice de assertividade quanto aos objetivos da pesquisa. $\mathrm{Na}$ IES B, o percentual de acertos foi maior que o das demais nas questões sobre abordagem, objetivos e procedimentos técnicos. $\mathrm{NaIES} \mathrm{C}$, o percentual de acertos quanto à natureza foi maior que o das demais. Porém, esta também apresenta o maior índice de desconhecimento e respostas erradas quanto à abordagem.

\subsection{SEGUNDA ETAPA DA PESQUISA}

A escala de respostas para a segunda etapa da pesquisa compreendeu quatro itens com a seguinte composição: (1) Desconheço; (2) Conheço superficialmente; (3) Conheço; e, (4) Conheço plenamente. Esta etapa teve como objetivo verificar como o aluno avalia o seu nível de conhecimento quanto à classificação da pesquisa científica. Os dados são apresentados na Tabela 06.

Tabela 6: Etapa 02 - Como o aluno avalia o seu conhecimento

\begin{tabular}{|c|c|c|c|c|c|}
\hline \multicolumn{2}{|c|}{ Conhecimento quanto à classificação da pesquisa científica } & 1 & 2 & 3 & 4 \\
\hline \multirow{2}{*}{ Sobre a natureza de pesquisa científica? } & Básica & 41 & 136 & 57 & 5 \\
\hline & Aplicada & 65 & 125 & 45 & 4 \\
\hline \multirow{2}{*}{ Sobre a abordagem de pesquisa científica? } & Quantitativa & 21 & 95 & 99 & 24 \\
\hline & Qualitativa & 22 & 95 & 97 & 25 \\
\hline \multirow{2}{*}{ Sobre os objetivos da pesquisa científica? } & Explicativa & 34 & 133 & 62 & 10 \\
\hline & Descritiva & 36 & 122 & 67 & 14 \\
\hline \multirow{8}{*}{$\begin{array}{l}\text { Sobre os procedimentos técnicos da } \\
\text { pesquisa científica? }\end{array}$} & $\begin{array}{l}\text { Pesquisa } \\
\text { bibliográfica }\end{array}$ & 18 & 91 & 100 & 30 \\
\hline & $\begin{array}{c}\text { Pesquisa } \\
\text { documental }\end{array}$ & 44 & 119 & 61 & 15 \\
\hline & $\begin{array}{c}\text { Pesquisa } \\
\text { experimental }\end{array}$ & 52 & 135 & 50 & 2 \\
\hline & $\begin{array}{l}\text { Levantamento } \\
\quad(\text { surveys })\end{array}$ & 88 & 104 & 42 & 5 \\
\hline & Estudo de caso & 19 & 94 & 99 & 27 \\
\hline & $\begin{array}{l}\text { Pesquisa } \\
\text { ex-post-facto }\end{array}$ & 130 & 86 & 20 & 3 \\
\hline & Pesquisa-ação & 94 & 108 & 32 & 5 \\
\hline & $\begin{array}{c}\text { Pesquisa } \\
\text { participante }\end{array}$ & 72 & 106 & 54 & 7 \\
\hline
\end{tabular}

Fonte: Dos autores (2015) 
O resumo estatístico sobre a avaliação do aluno quanto ao seu nível de conhecimento da pesquisa científica identificado nas IES é apresentado na Tabela 07.

Tabela 7: Resumo Estatístico - avaliação do aluno quanto ao nível de conhecimento

\begin{tabular}{|c|c|c|c|c|c|}
\hline \multicolumn{2}{|c|}{ Conhecimento da pesquisa científica } & \multirow{2}{*}{$\begin{array}{c}1 \\
17,2 \%\end{array}$} & \multirow{2}{*}{$\begin{array}{c}2 \\
56,9 \%\end{array}$} & \multirow{2}{*}{$\begin{array}{c}3 \\
23,8 \%\end{array}$} & \multirow{2}{*}{$\begin{array}{c}4 \\
2,1 \%\end{array}$} \\
\hline Sobre a natureza de pesauisa & Básica & & & & \\
\hline científica? & Aplicada & $27,2 \%$ & $52,3 \%$ & $18,8 \%$ & $1,7 \%$ \\
\hline \multirow{2}{*}{$\begin{array}{l}\text { Sobre a abordagem de pesquisa } \\
\text { científica? }\end{array}$} & Quantitativa & $8,8 \%$ & $39,7 \%$ & $41,4 \%$ & $10,0 \%$ \\
\hline & Qualitativa & $9,2 \%$ & $39,7 \%$ & $40,6 \%$ & $10,5 \%$ \\
\hline \multirow{2}{*}{$\begin{array}{l}\text { Sobre os objetivos da pesquisa } \\
\text { científica? }\end{array}$} & Explicativa & $14,2 \%$ & $55,6 \%$ & $25,9 \%$ & $4,2 \%$ \\
\hline & Descritiva & $15,1 \%$ & $51,0 \%$ & $28,0 \%$ & $5,9 \%$ \\
\hline \multirow{8}{*}{$\begin{array}{l}\text { Sobre os procedimentos técnicos da } \\
\text { pesquisa científica? }\end{array}$} & $\begin{array}{l}\text { Pesquisa } \\
\text { bibliográfica }\end{array}$ & $7,5 \%$ & $38,1 \%$ & $41,8 \%$ & $12,6 \%$ \\
\hline & $\begin{array}{c}\text { Pesquisa } \\
\text { documental }\end{array}$ & $18,4 \%$ & $49,8 \%$ & $25,5 \%$ & $6,3 \%$ \\
\hline & $\begin{array}{c}\text { Pesquisa } \\
\text { experimental }\end{array}$ & $21,8 \%$ & $56,5 \%$ & $20,9 \%$ & $0,8 \%$ \\
\hline & $\begin{array}{l}\text { Levantamento } \\
\quad(\text { surveys })\end{array}$ & $36,8 \%$ & $43,5 \%$ & $17,6 \%$ & $2,1 \%$ \\
\hline & Estudo de caso & $7,9 \%$ & $39,3 \%$ & $41,4 \%$ & $11,3 \%$ \\
\hline & $\begin{array}{c}\text { Pesquisa } \\
\text { ex-post-facto }\end{array}$ & $54,4 \%$ & $36,0 \%$ & $8,4 \%$ & $1,3 \%$ \\
\hline & Pesquisa-ação & $39,3 \%$ & $45,2 \%$ & $13,4 \%$ & $2,1 \%$ \\
\hline & $\begin{array}{l}\text { Pesquisa } \\
\text { participante }\end{array}$ & $30,1 \%$ & $44,4 \%$ & $22,6 \%$ & $2,9 \%$ \\
\hline
\end{tabular}

Fonte: Dos autores (2015)

Através da análise dos dados constantes nas perguntas realizadas na segunda etapa da pesquisa, no que tange à natureza, à abordagem, aos objetivos e aos procedimentos técnicos, $31,8 \%$ dos alunos pesquisados percebem seu nível de conhecimento como "conheço" e "conheço plenamente". Em contrapartida, o somatório dos níveis de conhecimento superficial e desconhecimento correspondem a $68,2 \%$.

Considerando que as pesquisas científicas realizadas por acadêmicos sejam sempre de natureza aplicada (PRODANOV; FREITAS, 2013), chama a atenção o percentual de 27,2\% dos alunos que apontaram desconhecer este 
conceito. Neste contexto, tambémé ressaltado o número de alunos que desconhecem o que são abordagens quantitativa e qualitativa, $8,8 \%$ e $9,2 \%$,respectivamente. A escolha da abordagem de pesquisa está relacionada ao objeto de estudo e como serão analisadas as hipóteses (HAIR, 2005), podendo comprometer o sucesso do trabalho, se houver uma escolha inadequada.

Em relação aos procedimentos técnicos das pesquisas, a pesquisa bibliográfica $(7,5 \%)$ e o estudo de caso $(7,9 \%)$ tiveram o menor índice de "desconheço", e a maior percentagem de “conheço plenamente”, com 12,6\% e 11,3\%,respectivamente. A pesquisa ex-post-facto $(54,4 \%)$ seguido pela pesquisa-ação $(39,3 \%)$ são as referidas com o maior índice de "desconheço".

$\mathrm{Na}$ relação entre as IES, a instituição $\mathrm{A}$ tem a maior percentagem de "desconheço", 34\%, sobre pesquisa aplicada, com resultados de $23 \%$ na IES B e 8,6\% na C. Em relação aos procedimentos técnicos da pesquisa científica, as três IES obtiveram, na opinião de seus alunos, resultados superiores a 50\% em "conheço" e "conheço plenamente" nas opções de pesquisa bibliográfica e do estudo de caso, podendo ser indicativo de maior utilização desses dois modos de pesquisa.

Neste sentido,o resultado deste estudo converge com o demonstrando por Linhares (2014), através de sua pesquisa entre discentes da Universidade Federal do Rio Grande do Sul UFRGS, que observou a falta de conhecimento dos acadêmicos para a disciplina de metodologia científica.Atendendo aos objetivos da pesquisa, os resultados apontam para um desconhecimento dos temas abordados na disciplina, fato este que dificultará o desenvolvimento acadêmico e a construção do conhecimento.

\section{CONSIDERAÇÕES FINAIS}

O estudo mostrou-se adequado para verificar o quanto os alunos de graduação em administração de Caxias do Sul identificam a natureza da pesquisa científica. Os resultados dos índices da alternativa “desconheço", somados às respostas erradas na primeira etapa do questionário, apontaram que pelo menos um terço do grupo pesquisado não soube identificar corretamente as respostas. Apesar de todos os discentes pesquisados terem cursado a disciplina que aborda o tema e terem que apresentar um Trabalho de Conclusão de Curso (TCC) para receber seus diplomas, os graduandos mostraram pouco conhecimento em metodologia de pesquisa.

Enquanto este cenário se apresentar desta forma, as pesquisas tenderão a resultar em produções científicas de menor qualidade, pois a correta escolha do método influencia nas análises dos dados. Tendo em vista que os resultados provenientes de uma pesquisa elaborada com rigor metodológico possibilitarão contribuir para a construção do conhecimento,faz-se necessário que os acadêmicos, principalmente na graduação, tenham o domínio dos temas relacionados à metodologia da pesquisa.

$\mathrm{Na}$ segunda parte do estudo, cujo objetivo era verificar quanto os alunos de administração supõe saber sobre a metodologia, no que se refere à natureza da pesquisa, os resultados foram similares aos encontrados na primeira etapa, sendo apurado que $30 \%$ dos graduandos admitem desconhecer ou conhecer pouco os tópicos abordados no questionário. O conhecer plenamente não ultrapassa a $15 \%$ de qualquer 
questão aplicada, apontando para falta de domínio sobre o tema. Esses dados indicam que os acadêmicos de administração em Caxias do Sul não possuem o domínio necessário para a construção de uma pesquisa científica.

Os resultados verificados no ambiente das IES de Caxias do Sul convergem com as conclusões que Linhares (2014) apontou em seu estudo com mestrandos da Universidade Federal do Rio Grande do Sul -UFRGS, no qual o índice apontado denotou a falta de domínio da pesquisa científica entre os alunos. Esta comparação, embora caracterizada por universos de pesquisa diferentes (Graduação e Mestrado), não pode ser omitida, pois, mesmo que o propósito das disciplinas de metodologia científica na graduação seja o da preparação dos graduandos no que tange à realização de pesquisas e seus respectivos Trabalhos de Conclusão de Curso,é factível considerar que o domínio desta metodologia propiciaria uma base de conhecimento necessária para os discentes que venham a optar por ingresso em programas de pós-graduação, na sua forma mais ampla, seja lato ou strictosensu. É importante destacar algumas limitações deste estudo, dentre elas a questão geográfica, em que o estudo se restringiu à cidade de Caxias do Sul, e o ambiente de pesquisa reservado somente ao curso de administração.Para estudos futuros, sugere-se a análise em outros cursos de graduação e a ampliação do universo de pesquisa em termos geográficos, abrangendo polos, regiões e outros estados. Outro aspecto que pode ser abordado em pesquisas futuras é a identificação dos fatores que caracterizam maior ou menor entendimento e domínio sobre metodologia da pesquisa por parte dos alunos. Ainda, de maneira mais específica, verificar se existe alguma relação entre o método de ensino praticado pelos docentes e a qualidade da produção científica por parte dos acadêmicos. 
SCIENTIFIC

RESEARCH:

KNOWLEDGE

AND PERCEPTION

OF BUSINESS

ADMINISTRATION

STUDENTS FROM

CAXIAS DO SUL

ABSTRACT

From graduation, the research methodology starts to play a fundamental role in the development and preparation of university students for the elaboration of scientific research. Based on the criteria and scientific rigor required by the research, the study aims to verify the level of knowledge of the students about the classification of scientific research and evaluate how they perceive their level of knowledge regarding the classification of scientific research, about its nature, approach, objectives and technical procedures. The study was carried out with a sample of 239 Business Administration students in five higher education institutions in the city of Caxias do Sul, Brazil, using structured questionnaires, with a quantitative approach and descriptivepurposes. The resultsindicated that most of the students present lack of knowledge or superficial knowledge regarding the methodology of scientific research.

Keywords: scientific research, university students, business administration, knowledge.

\section{REFERÊNCIAS}

ADAMS, John et al. Research Methods for Business and Social Science Students. SAGE Publications. Índia, 2014.

ANDIFES - Associação Nacional dos Dirigentes das Instituições Federais de Ensino Superior. 2014. Disponível em: <http://zip.net/bvtyrZ>. Acesso em: 20 jul. 2014.

BARROS, A. J. P; LEHFELD, N. A. de S. Fundamentos de metodologia: um guia para a iniciação científica. 2. ed. ampliada. São Paulo: Makron Books, 2000.

BARROS, Aidil J. da Silveira; LEHFELD, Neide Aparecida de souza. Fundamentos de Metodologia científica. 3. ed. São Paulo: Pearson Prentice Hall, 2007.

BERTERO, Carlos Osmar; CALDAS, Miguel Pinto; WOOD JR, Thomaz. Produção científica em administração de empresas: provocações, insinuações e contribuições para um debate local. Revista de Administração Contemporânea, v. 3, n. 1, p. 147178, 1999.

BRASIL. Instituto Nacional de Estudos e Pesquisas Educacionais Anísio Teixeira - INEP. Disponível em: <http://zip.net/bwtxvj>. Acesso em: 20 jul. 2014.

. Ministério da Educação - MEC. 2014.

Disponível em: <http://zip.net/bkslky>. Acesso em: 20 jul. 2014.

COLLIS, J.; HUSSEY, R. Pesquisa em administração: um guia prático para alunos de graduação e pós-graduação. 2. ed. Porto Alegre: Bookman, 2005

COOPER, Donald R.; SCHINDLER, Pamela. Métodos de Pesquisa em Administração. 7. ed. Porto Alegre: Bookman, 2003.

DEMO, Pedro. Metodologia científica em ciências sociais. São Paulo: Atlas, 1985.

Metodologia do conhecimento científico. São Paulo: Atlas, 2000.

FACER, Keri. The problem of the future and the possibilities of the present in education research. International Journal of Educational Research, v. 61, p. 135-143, 2013. 


\section{SOBRE OS AUTORES}

HAIR, Joseph F. Fundamentos de métodos de pesquisa em administração. Porto Alegre: Bookman, 2005.

HARTLEY, Jean F. Case studies in organizational research. In: CASSELL, Catherine; SYMON, Gillian (Ed.). Qualitative methods in organizational research: a practical guide. London: Sage, p. 208-229, 1994.

IBGE - Instituto Brasileiro de Geografia e Estatística. 2014. Disponível em: <http://zip.net/ bsIN3P>. Acesso em: 20 jul. 2014

KÖCHE, José Carlos. Fundamentos de metodologia científica: teoria da ciência e iniciação à pesquisa. 31. ed. Petrópolis, RJ: Vozes, 2012.

LAKATOS, Eva Maria; MARCONI, Marina de Andrade. Metodologia científica. São Paulo: Atlas, 1991.

LINHARES, Bianca de Freitas. O ensino de metodologia de pesquisa na visão de alunos de Ciências Sociais e de Ciência Política. Revista Espaço Pedagógico, v. 21, n. 1, 2014.

MESQUITA, Rafael Fernandes de et al. Óbices metodológicos da prática de pesquisa nas ciências administrativas. Revista Pensamento Contemporâneo em Administração, v. 8, n. 1, p. 50-65, 2014.

PRESTES, Adriano Reci; ANDREOLA, Jocélia Felícia; OLEA, Pelayo Munhoz. Percepções sobre ensino de metodologia de pesquisa no mestrado. Revista Pretexto, v. 11, n. 2, 2011.

PRODANOV, Cleber Cristiano. FREITAS, Ernani Cesar. Metodologia do trabalho Científico: métodos e técnicas da pesquisa e do Trabalho Acadêmico. 2. edição. Novo Hamburgo: Feevale, 2013.

SAMPIERI, Roberto Hernández; COLLADO, Carlos Fernández; LUCIO, Pilar Baptista.

Metodologia da Pesquisa. Trad: Penso Editora, 2013.

STRAUSS, A.; CORBIN, J. Pesquisa qualitativa: técnicas e procedimentos para o desenvolvimento de teoria fundamentada. Porto Alegre: Artmed/ Bookman, 2008.

Data de recebimento: $11 / 08 / 2015$

Data de aprovação: 13/12/2016

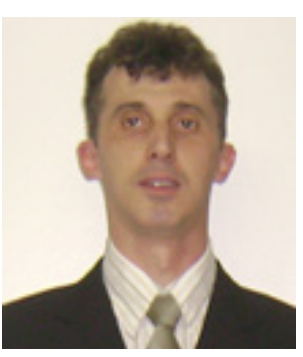

Sandro Manoel

Machado

Mestre em Administração de Empresas pela Universidade de Caxias do Sul(UCS), pós-graduado em Logística das Operações Empresariais e graduado em Ciências Contábeis pela Universidade Luterana do Brasil (ULBRA). Atuou como Gestor de Operações e de Filiais em empresas de Logística e Transportes. Atualmente é consultor nas áreas de Gestão de Processos,Logística eTransportes.Docente em curso Técnico de Logística e Supply Chain Management.

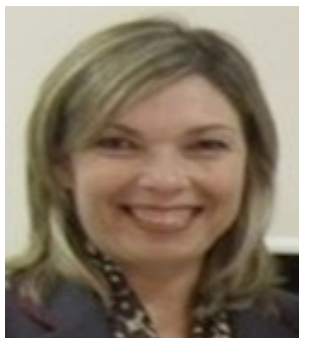

\section{Andrea Cristina Fermiano Fidelis}

Psicóloga graduada pela Universidade do Vale do Rio dos Sinos (Unisinos) e mestra em Administração pela Universidade de Caxias do Sul (UCS). Doutoranda em Marketing e Estratégia pela Universidade de Aveiro (UA). Atuou como Gestora em Recursos Humanos em empresas do segmento de saúde e empresas de tecnologia. Trabalhou como docente em cursos de especialização e escolas técnicas nas áreas de Psicologia aplicada a saúde e a gestão de Recursos Humanos.

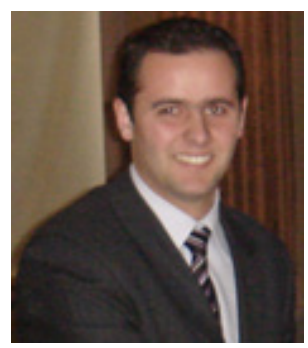

\section{Isaias Ricardo Carraro}

Mestrado em Administração - UCS (2016). MBA em Gestão Estratégica de Produção - UCS (2013). MBA em Gestão de Operações Logísticas e Supply Chain - Faculdade da Serra Gaúcha - FSG (2012). Graduado em 
Administração de Empresas - UCS (2010). Diplomado em Logística Integral - Pontifícia Universidad Javeriana (Bogotá - Colômbia - 2006). Diplomado em Gerência de Projetos - Universidad de La Sabana (Bogotá - Colômbia - 2004). Tradutor Público Juramentado e Intérprete Comercial nos idiomas Português/Espanhol. Professor e Coordenador dos cursos de Graduação em Logística / Gestão Comercial / Gestão de Recursos Humanos na Faculdade da Serra Gaúcha - FSG (Caxias do Sul). Professor e Coordenador dos cursos Técnicos: Logística / Transações Imobiliárias no Instituto Cultural e Desportivo Mutirão

\section{Pelayo Munhoz Olea}

Bolsista do CNPq/BRASIL. Pós-Doutorado em Gestão Ambiental pelaUniversidad de Extremadura, UEX, Espanha, Bolsista do Programa América
Latina Formación Académica ALFA2 da Rede Jean Mermoz/ESPAÑA. Doutorado em Administração e Direção de Empresas pela Universitat Politècnica de Catalunya, ETSEIB/UPC, Espanha, Bolsista da Coordenação de Aperfeiçoamento de Pessoal de Nível Superior, CAPES/BRASIL. Mestrado em Engenharia de Fabricação de Papel pela Universitat Politècnica de Catalunya,ETSEIAT/UPC,Espanha, Bolsista do Instituto de Cooperación Iberoamericana, ICI/AECI/ESPAÑA.Graduaçãoem Administração de Empresas pela Pontifícia Universidade Católica do Rio Grande do Sul, PUCRS e Graduação em Engenharia Mecânica pela Pontifícia Universidade Católicado Rio Grandedo Sul,PUCRS.Atualmente é Professor da Universidade de Caxias do Sul, UCS. 
